www.jmscr.igmpublication.org

Impact Factor 5.244

Index Copernicus Value: 83.27

ISSN (e)-2347-176x ISSN (p) 2455-0450

crossref DOI: http://dx.doi.org/10.18535/jmscr/v4i8.67

\title{
Clinical Significance of Anatomical Variations in Ostiomeatal Complex As Detected By MDCT
}

\author{
Authors \\ Dr N.L.N Moorthy, Dr D.Mahesh Chander, Dr Mounika K, Dr Madhavi Latha \\ Department of Radiodiagnosis, Gandhi Medical College and Hospital, \\ Secunderabad, Telangana-500003, India \\ Corresponding Author \\ Dr Mounika K \\ Junior Resident, Department of Radiodiagnosis, \\ Gandhi Medical College and General Hospital, Secunderabad, Telangana \\ Email:mouni.kadipikonda@gmail.com,moorthynin@rediffmail.com, Mobile-9493263867
}

\begin{abstract}
Infections involving paranasal sinuses and nasal cavities is one of the common public health problem in all age groups. Functional endoscopic sinus surgery has revolutionized in the treatment of sinusitis. MDCT has been the most ideal investigation in the assessment of paranasal sinuses especially in the identification of various anatomical variations that predispose to development of sinus infection. The present study was done to detect the presence of significant anatomical variations in the ostiomeatal complex, the main drainage point of sinus in 300 symptomatic patients.

Keywords- ostiomeatal complex, anatomical variations, sinusitis
\end{abstract}

\section{Introduction}

OMC is the most important drainage route for the paranasal sinuses in the skull of which the anterior OMC is the major draining ostia, as it drains the maxillary sinus, frontal sinus, anterior part of ethmoidal sinus whereas posterior OMC drains posterior part of ethmoid and sphenoid sinus. The components that form OMC are maxillary ostium, ethmoidal infundibulum, anterior ethmoidal air cells, frontal recess. Various anatomical variations in the development of these structures critically Introduction affect the drainage of sinuses resulting in recurrent sinus infections. Besides the OMC other structures that form the lateral wall of nasal cavity also aid in the development of sinusitis.

The major anatomical variations that predispose to development of sinus infections are uncinate process anomalies, pneumatization/concha, haller air cell expansion and giant ethmoidal bulla.

\section{Materials and Methods}

A retrospective analysis of the coronal CT scan images of paranasal sinus was done in 300 patients who are referred with clinical diagnosis of sinus disease. CT scan was performed on 16 slice MDCT Evanto 16 of semens 1 td at $1 \mathrm{~mm}$ thin coronal images. 
The main anatomical points that were consider in the study include 1) uncinate process 2) nasal turbinate or concha 3) nasal septum 4) ethmoidal air cell variants.

\section{Discussion}

MDCT is the most essential imaging in the detect nasal cavities and paranasal sinuses ${ }^{(1,2,3,4,5)}$. OMC is the main anatomical unit that aids in the drainage of paranasal sinuses. The structures included in OMC are maxillary sinus ostium, infundibulum, middle meatus complex, anterior and middle ethmoidal air cells ostea and frontal recess ${ }^{(6)}$. Precise anatomy of the OMC is very crucial in performing the Functional endoscopic sinus surgery in patients presenting with recurrent and persistent sinusitis. Many significant anatomical variations in the development of OMC have been described in the literature, which are responsible for the recurrence of sinus infection due to obstruction to mucociliary clearance. According to different studies reported the most frequent anatomical variation being concha bullosa ${ }^{(7,8,9)}$ followed by deviated uncinate process $^{(10)}$, deviated nasal septum ${ }^{(11,12,13)}$ and paradoxical thickened middle turbinate ${ }^{(14)}$.

The most frequent anatomical variation involving uncinate process, concha, ethmoidal infundibulum of which uncinate process anomalies are the most common type seen in sinusitis ${ }^{(15)}$. The variations in the uncinate process include a)elongation b)medial deviation c)lateral deviation d)pneumatization e)spur f)absent uncinate process. Elongation of uncinate process is the most common anomaly of uncinate process followed by pneumatization. Pneumatization of concha also called as concha bullosa is also relatively common anomaly usually involves the middle turbinate. Expanded concha bullosa compresses the uncinate process and narrows the ethmoidal infundibulum. Other anomalies of turbinate that similarly affect the ethmoidal infundibulum including accessory turbinate, duplicate turbinate, paradoxical turbinate and giant ethmoidal bulla, expanded haller air cells.

Deviated nasal septum is one of the common clinical problem seen in sinusitis.DNS results in compensatory hypertrophy of turbinate and bulla on opposite side.

Uncinate process is one of the most important structure in the nasal cavity as various types of anatomical variations has been documented in the literature ${ }^{(16,17,18,19)}$. After uncinate process the next most important bone structure that shows developmental variation is turbinate or concha, though all the different variation may not result in nasal obstruction. concha bullosa/pneumatization of the concha is the most frequent variation noted in major studies ${ }^{(20)}$, involving middle concha mostly, also can occur in superior, inferior concha. Pneumatization of concha is classified into lamellar,bulbous and extensive depends on the location of pneumatization ${ }^{(21)}$. We found no significant relationship between sinus disease and a type of concha bullosa. Besides the common pneumatized turbinate ${ }^{(2)}$, often found bilateral paradoxical superior turbinate, unilateral paradoxical inferior turbinate, unilateral accessory middle turbinate. Pneumatization of multiple turbinate was reported ${ }^{(20)}$. Extremely rare cause of anomalies like septal concha bullosa ${ }^{(23)}$, absent middle turbinate also reported ${ }^{(24)}$

A strong association has been reported between the presence of concha bullosa and contralateral deviation of nasal septum with no significant increase in incidence of sinus disease ${ }^{(25)}$

In the present retrospective study of CT imaging of paranasal sinuses in 300 patients all age groups were covered

\section{Age distribution}

\begin{tabular}{|l|c|c|c|c|c|c|c|}
\hline age & $0-10$ & $11-20$ & $21-30$ & $31-40$ & $41-50$ & $51-60$ & $61-70$ \\
\hline number & 4 & 36 & 111 & 89 & 37 & 16 & 7 \\
\hline
\end{tabular}


Males are more frequently affected than females.

\section{sex distribution}

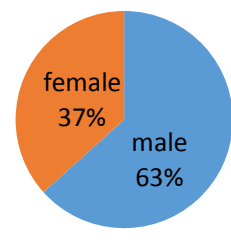

The most frequent anomaly noted was nasal septal deviation 226 out of $300(75 \%)$ followed by anomalies of middle turbinate

\begin{tabular}{|c|c|}
\hline List of anomalies & Frequency \\
\hline septum & 226 \\
\hline Turbinate & 153 \\
\hline Uncinate process & 119 \\
\hline Giant ethmoid & 62 \\
\hline Haller cells & 20 \\
\hline
\end{tabular}

The nasal septal deviation to either side was more or less equal.

Septal anomalies

\begin{tabular}{|l|c|}
\hline right & 85 \\
\hline left & 72 \\
\hline Right with spur & 26 \\
\hline Left with spur & 23 \\
\hline S shape & 20 \\
\hline
\end{tabular}

Pneumatization is the most frequent anomaly noted in middle turbinate (33\%). In 5 patients superior turbinate showed pneumatization which was extremely rare finding. In one case middle turbinate was absent. In 44 cases pneumatization or hypertrophied turbinate was associated with contralateral deviation of nasal septum.

\begin{tabular}{|l|l|}
\hline Middle turbinate pneumatization & 100 \\
\hline Paradoxical turbinate & 27 \\
\hline Hypoplastic turbinate & 26 \\
\hline Superior turbinate pneumatization & 5 \\
\hline Absent middle turbinate & 1 \\
\hline
\end{tabular}

Medial or lateral deviation of uncinate process was with equal incidence in some patients.

Uncinate process anomalies

\begin{tabular}{|l|c|}
\hline medial & 40 \\
\hline lateral & 39 \\
\hline elongated & 18 \\
\hline pneumatization & 17 \\
\hline absent & 5 \\
\hline
\end{tabular}

Expanded ethmoid sinus or bulla also causes narrowing of ethmoidal infundibulum by displacing the uncinate process laterally. In our study we found 62 cases of giant ethmoidal bulla (20.6\%) compromising OMC. M

Air cells seen at inferomedial wall of orbit also called as haller air cells also block the maxillary sinus ostium.we found 20 cases of haller air cells (6.6\%) obstructing or displacing the uncinate process.

The incidence of various anatomical variations in our study was almost as par with other similar studies done previously.

Precise anatomical evaluation or detection of variations was found with MDCT using thin sections. These type of anamolies before planning functional endoscopic sinus surgery will result in precise patient care or management by avoiding complications during surgery.

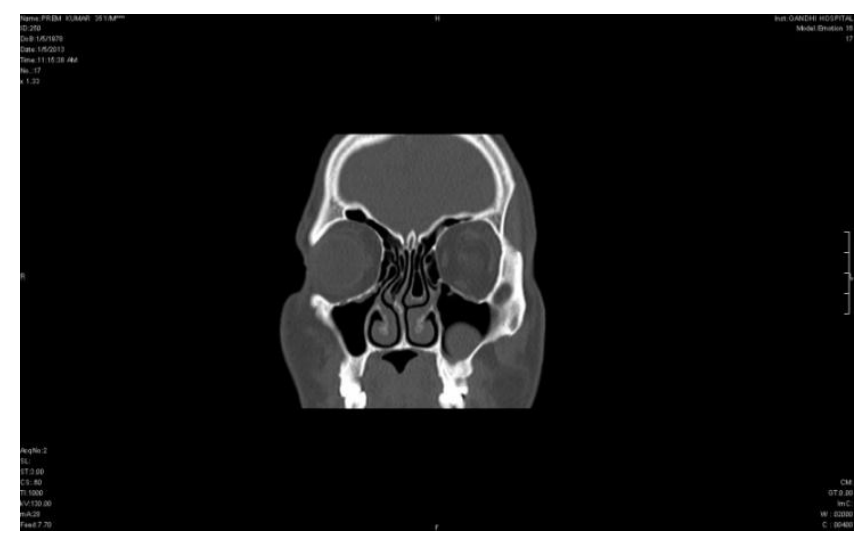

CT coronal imaging showing Septal spur to right side

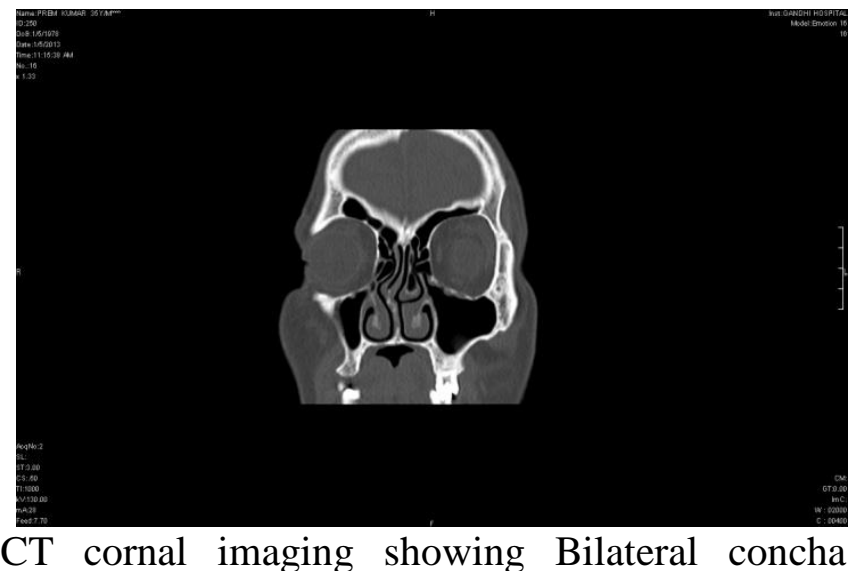
bullosa 


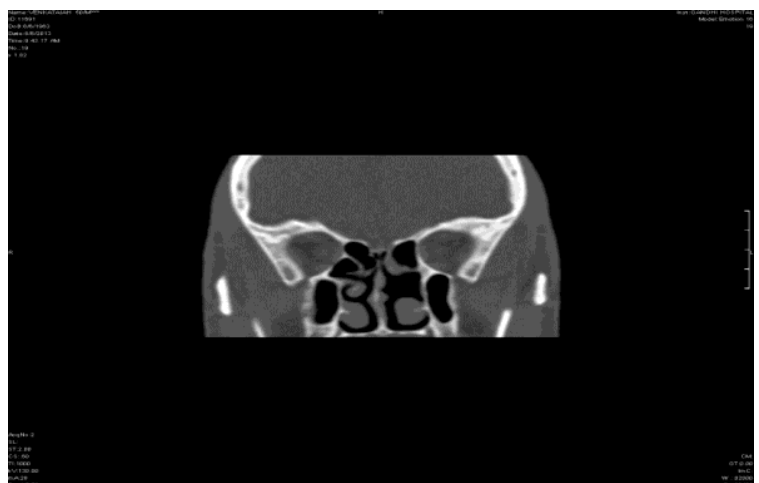

CT PNS coronal imaging showing Congenital absence of left middle turbinate

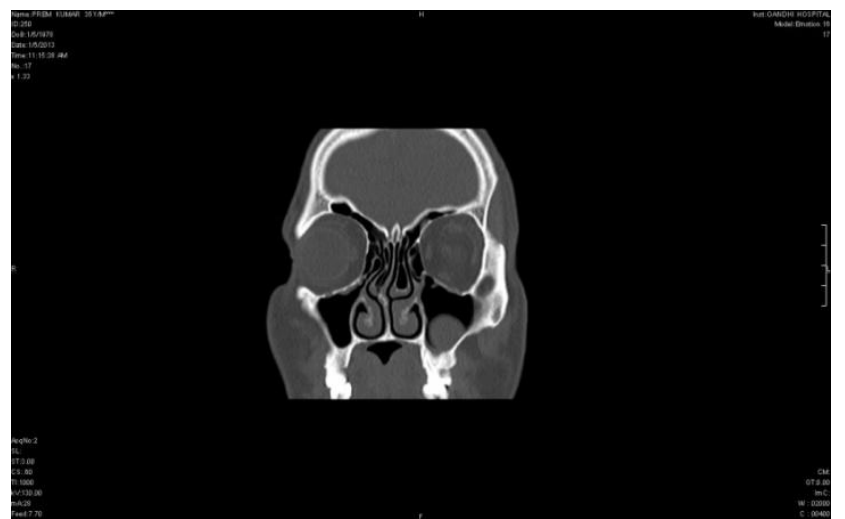

CT PNS coronal imaging showing bilateral medial deviation of uncinate process

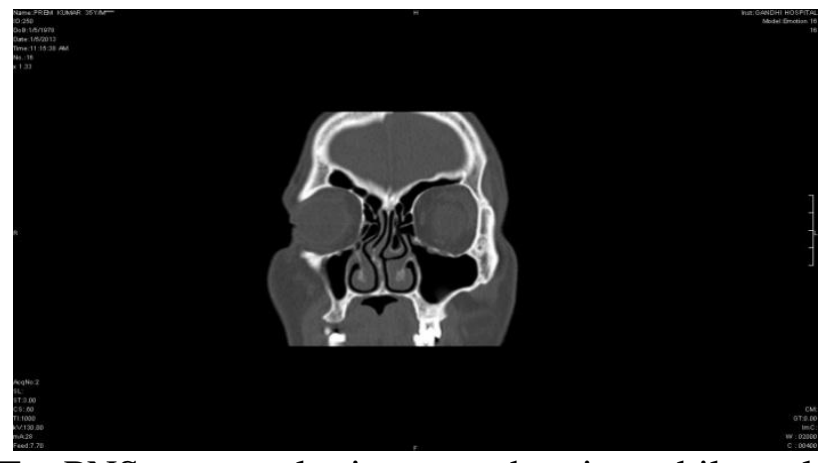

CT PNS coronal image showing bilateral elongated Uncinate process

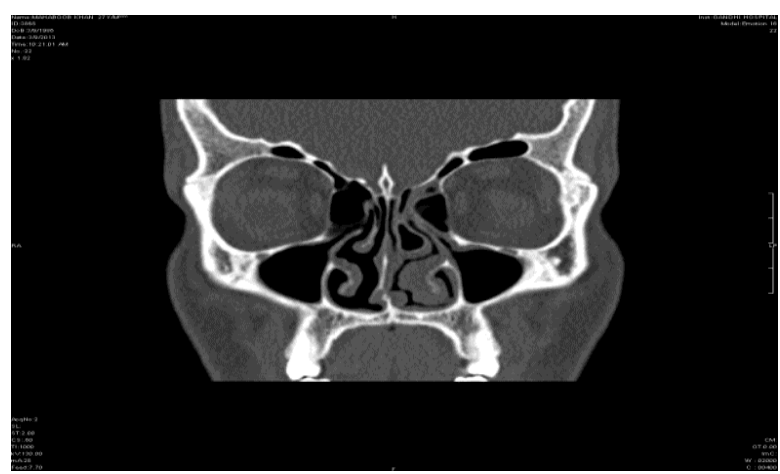

CT PNS coronal image showing bilateral elongated Uncinate process

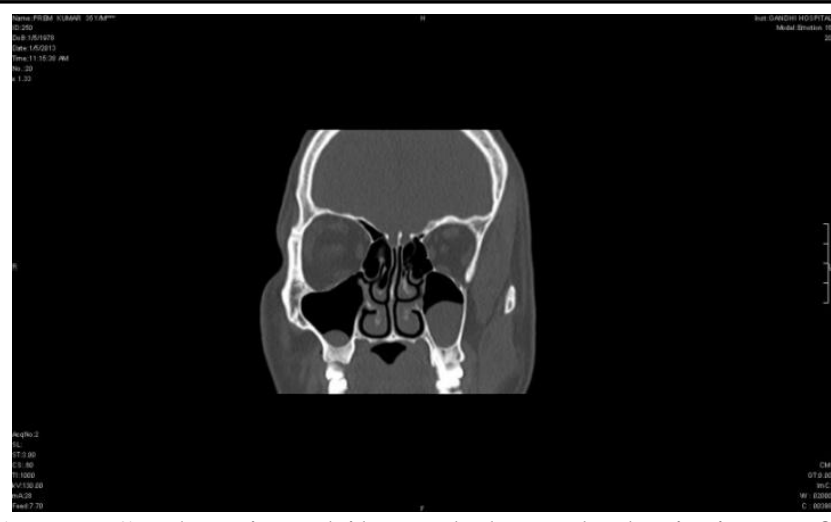

CT PNS showing bilateral lateral deviation of uncinate process

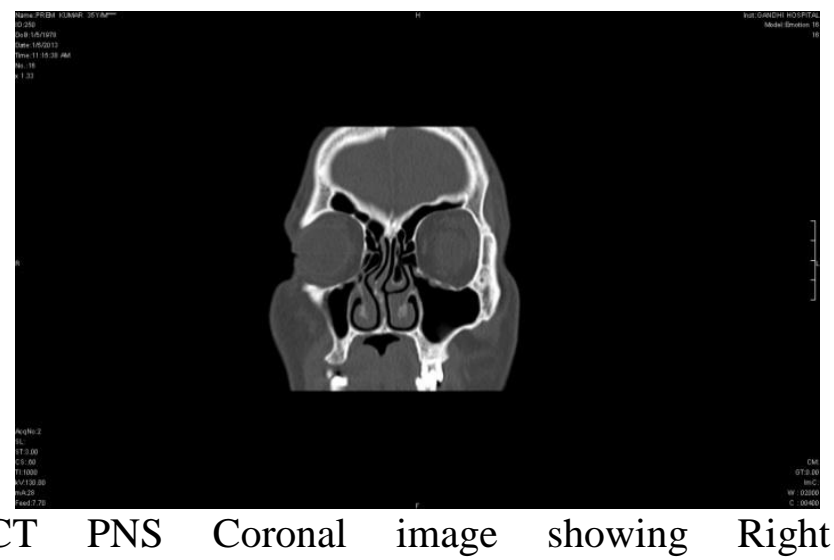
pneumatized uncinate

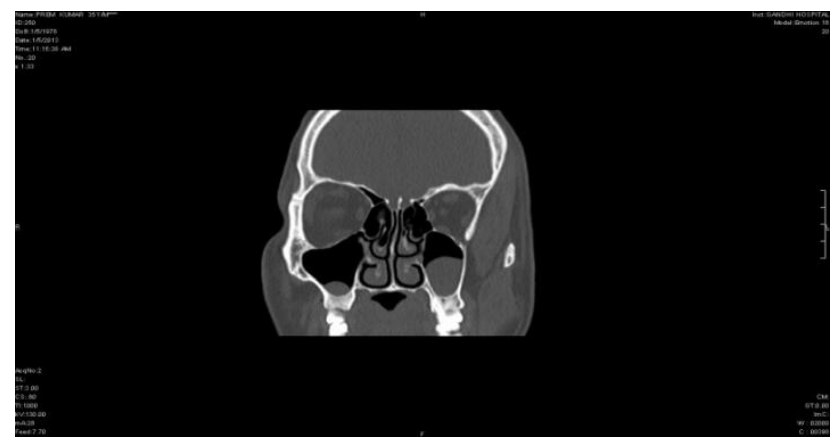

CT PNS coronal image showing Bilateral giant ethmoid bullae

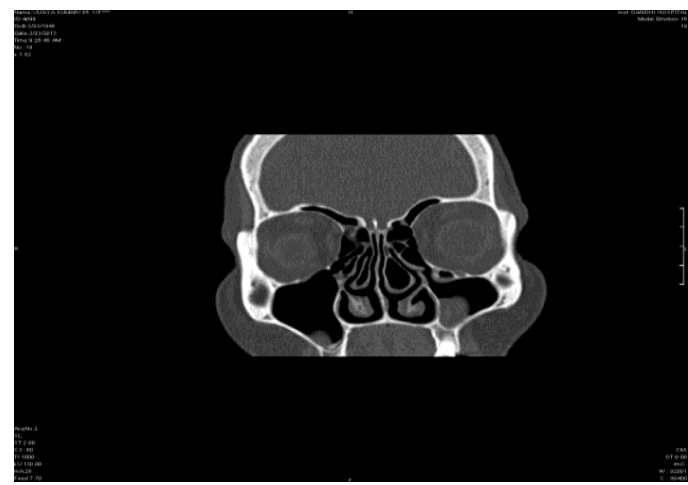

CT PNS coronal imaging showing left haller cell. 


\section{Conclusion}

MDCT is most valuable in the evaluation of paranasal sinus in patients with sinusitis before contemplating functional endioscopic sinus surgery.

\section{References}

1. Ricardo Pires de souza, Joel Pinheiro de Brito Junior et al. Sinonasal Complex: Radiological Anatomy. Radiol Bras 2006;39(5):367-372

2. Amit N D Dwivedi, Kapil Kumar Singh.CT Of the Paranasal Sinuses: Normal Anatomy Variants and Pathology. Journal of optoelectronics and Biomedical Materials vol .2, Issue 4,octoberDecember 2010,p.281-289

3. Christianamaia Nobre Rocha de Miranda,Carol Pontes de Miranda Maranhao et al. Anatomical variations of paranasal sinuses at multislice computed tomography: what to look for.Radiol Bras.2011Jul/Aug;44(4):256-262

4. Uma Devi Murali Appavoo Reddy, Bhawna Dev. Pictorial essay: Anatomical variations of paranasal sinuses on multidetector computed tomography-How does it help FESS surgeons. Indian journal of Radiology and Imaging/ November 2012/vol 22/Issue 4

5. Sanjayvaid, Neelamvaid. Normal anatomy and Anatomic variants of the paranasal sinuses on Computed Tomography. Neuroimaging Clinics North America 25 (2015)527-548

6. Maffe, valvasori, Becker. Imaging of the Head and Neck, $2^{\text {nd }}$ edition.page no.367

7. S.A.R.Nouraei,A.R/Elisay,S.A.Madani,P.J .Andrews. Variations in paranasal sinus Anatomy: Implications for the pathophysiology of Chronic Rhinosinusitis and Safety of Endoscopic Sinus Surgery. Journal of Otolaryngology-Head \&Neck Surgery, Vol 38,No 1(February),2009:pp 32-37
8. Asif A. Wani, Sohit Kanotra et al. CT scan evaluation of te anatomical variations of the ostiomeatal complex. Indian J Otolaryngol Head Neck Surg(JulySeptember2009)61:163-168

9. Rashid AI-Abri, Deepa Bhargava et al.Clinically Significant Anatomical Variants of the Paranasal Sinuses. Oman Medical Journal(2014)Vol.29,No.2:110113

10. H. Mamatha, N.M. Shamsunder et al. Variations of ostiomeatal complex and its applied anatomy:a CT scan study. Indian Journal of Science and Technology vol.3 No.8(Aug 2010)ISSN:0974-6846

11. Dr Mirza Aneesa Afzal, Dr Aijaz ul Haq et al. Ct Evaluation of Anatomical Variations In Osteomeatal Complex in Patients with Deviated Nasal Septum. IJSR-International Journal of Scientific Research, vol:2lis:9/Sept 2013.ISSN No 2277-8179

12. Anita Aramani, R.N.Karadi et al. A Study of Anatomical Variations of Osteomeatal Complex in Chronic Rhinosinusitis Patients-CT Findings. Journal of Clinical and Diagnostic Research.2014 Oct,vol8(10):KCo1-KC04

13. Mohammed Atik Ahmed, suresh Kanmadi. Role of Computed tomography in Evaluation of Congenital Anatomical Variations in Paranasal Sinuses. Int J Biol Med Res.2015;6(1):4775-4781

14. Jain P.K,Arora $\mathrm{N}$ et al.Computerized Tomographic Evaluation of Anatomical Variations of Paranasal Sinus Region and their Clinical Importance. International Journal of Medical and Applied Sciences, Vol. 3,Issue 4,2014 E-ISSN:2320-3137

15. Belachew Tessema, Arlen D Meyers. Nasal Cavity Anatomy, Physiology and Anomalies on CT Scan. http://emedicine.medscape.com/article/875126overview\#a4

16. WilliamE.Bolger, William Woodruff et al. CT Demonstration of Pneumatization of 
the Uncinate Process.www.ajnr.org/content/11/3/552

17. VasilicaBaldea, Mihail Dan Cobzeanu et al. Anatomical variants of the uncinate process-CT scan imaging study.Romanian Journal of Rhinology,Vol.2,No.7,JulySeptember 2012

18. Gnanavelraja C,Senthilnathan V et al. Anatomical Variations in the superior attachment of uncinate process and its association with frontal sinusitis. MedPulse-International Medical Journal August 2014;1(8):399-401.

19. N.Vinaykumar,E.Kamala et al. A Computerized Tomographic Study of Uncinate Process of Ethmoid Bone. International Journal of Anatomy and Research, Int J Anat Res 2015,Vol 3(1):917-21.ISSN 2321-4287

20. Ozcan KM,Selcuk A et al. Anatomical variations of nasal turbinates. JCraniofac Surg.2008 Nov;19(6):167882.doi:10.1097/SCS.Obo13e318188a29d

21. Hatice Gul Hatipoglu, Mehmet Ali Cetin, Enis Yuksel. Concha bullosa types:their relationship with sinusitis, ostiomeatal and frontal recess disease.Head and Neck Imaging. Diagn Intervent Radiol 2005;11:145-149

22. MaruN, RusuMC, SandulescuM. Variant anatomy of nasal turbinates: supreme, superior and middle conchae bullosae, paradoxical superior and inferior turbinates,and middle accessory turbinate. Rom J Morphol Embryol.2015;56 (3):1223-6.

23. A.Peric , N.Baletic, J.Sotirovic. A case of an uncommon anatomic variation of the middle turbinate associated with headache. Acta Otorhinolaryngologica Italica 2010;30:156-159.

24. Marco FERRARI, Manfred TSCHABITSCHER et al. A case of middle turbinate absence. International Journal of Anatom- ical Variations (2015)8:12-14.Eissn 13084038.

25. Jamie S.Stallman,JoaoN.Lobo and Peter M.Som. The Incidence of Concha Bullosa and Its Relationship to Nasal Septal Deviation and Paranasal Sinus Disease. American Journal of Neuroradiology 2004 25:1613-1618. 